\title{
YÊU TỐ TIÊN LƯợNG CỦA THÂT BẠI VỚI TUÂN HOÀN FONTAN GIAI ĐOẠN SỚM: KẾT QUẢ SAU 8 NĂM TRIỂN KHAI PHẪU THUẬT FONTAN
}

\section{TÓM TẮT}

Mục tiêu: nghiên cứu được tiến hành nhằm đánh giá kết quả sau phẫu thuật Fontan ở nhóm bệnh nhân tim sinh lý 1 thất, xác định tỉ lệ thất bại với tuần hoàn Fontan ở giai đoạn sớm (early Fontan failure- EFF) và sơ bộ khảo sát các yếu tố nguy cơ trên nhóm bệnh nhân này. Đối tượng và phương pháp: tổng số 145 bệnh nhân đã được tiến hành phẫu thuật Fontan tại Trung tâm tim mạch- Bệnh viện $\mathrm{E}$ trong giai đoạn từ tháng 8/2012 đến 12/2019. Kết quả sau mổ được tập trung nghiên cứu và phân tích là tình trạng thất bại với tuần hoàn Fontan ở giai đoạn sớm (EFF). Kết quả: tỷ lệ gặp $\mathrm{EFF}$ trong nghiên cứu là 9,66\% (14 trường hợp, trong đó có 13 trường hợp tử vong và 1 trường hợp chấm dứt tuần hoàn Fontan). Phân tích đơn biến với các biến số trước mổ chỉ ra một số yếu tố nguy cơ liên quan với EFF bao gồm: thể bệnh giải phẫu thông sàn nhĩ thất thể không cân xứng, bất thường đảo ngược phủ tạng, tình trạng hở van nhĩ thất từ trước mổ, tuần hoàn bàng hệ chủ- phổi lớn phát hiện trên siêu âm, tình trạng tăng áp lực động mạch phổi và tăng sức cản hệ mạch máu phổi trước mổ. Phân tích đơn biến với các yếu tố trong quá trình phẫu thuật có liên quan với EFF bao gồm: tiến hành tạo hình động mạch phổi hoặc sửa van nhĩ thất cùng thời điểm phẫu thuật Fontan, tăng áp lực động mạch phổi, và tình trạng chảy máu trong mổ. Dấu hiệu phù ngay sau mổ cũng có liên quan chặt chẽ với EFF. Tổng số 22 yếu tố nguy cơ được tiến hành khảo sát và phân tích đa biến, xác định được 3 yếu tố độc lập thực sự làm gia tăng nguy cơ EFF sau mổ: tăng áp lực động mạch phổi trước mổ (OR: 1.84, 95\%CI: $1.12-3.00$, $\mathrm{p}=0.016$ ), tiến hành sửa van nhĩ thất cùng thời điểm phẫu thuật Fontan (OR: 65.85, 95\%CI: 1.95-2228.14, $\mathrm{p}=0.020)$, và tình trạng tăng áp lực động mạch phổi ngay sau mổ (OR: 1.66, 95\%CI:
1.19-2.33, p=0.004). Kết luận: trong nghiên cứu này, tỉ lệ EFF sau phẫu thuật Fontan còn tương đối cao, và là nguyên nhân chính của tỉ lệ tử vong sau mổ. Tình trạng tăng áp lực động mạch phổi trước và ngay sau mổ, cùng với tiến hành sửa van nhĩ thất cùng thời điểm phẫu thuật Fontan là các yếu tố nguy cơ độc lập liên quan đến EFF sau mổ.

\section{ABSTRACT}

Although early postoperative outcomes after Fontan have improved in the modern era, the convincing evidence in the resource-scare setting was sparse. Our study aimed to characterize the incidence of early Fontan failure (EFF) in a contemporary series of palliated patients and to identify its potential risk factors in these patients. A single-center retrospective study was conducted between August 2012 and December 2019 on 145 patients undergoing the Fontan procedure. The primary outcome of interest was EFF, defined as death, Fontan takedown, or listing for heart transplantation prior to hospital discharge or within 30 postoperative days. The incidence and outcomes were summarized with descriptive statistics, and risk factors for EFF were identified with both univariable and multivariate logistic regression. The incidence of EFF was $9.66 \%(n=14$ : thirteen deaths, and one Fontan takedown). In the univariate analysis for pre-operative data, the anatomical diagnosis of unbalanced atrioventricular (AV) septal defect, situs inversus form, AV valve regurgitation, large aorta-pulmonary circulation in Doppler echocardiography, elevated

\footnotetext{
* Trung tâm Tim mạch Bệnh viện E.

** Bệnh viện Nhi Trung Uong

Người chịu trách nhiệm khoa học: Trần Đắc Đại

Ngày nhận bài: 02/08/2020 - Ngày Cho Phép Đăng: 04/09/2020

Phản Biện Khoa học: PGS.TS. Đoàn Quốc Hung PGS.TS. Nguyễn Hũu U'ơcc
} 
pulmonary artery pressure (PAP), and elevated pulmonary vascular resistance (Rp) were significantly associated with EFF. At the Fontan, four risk factors influencing EFF included pulmonary artery reconstruction, AV valve repair, bleeding, and elevated PAP. Postoperative edema was also significantly associated with EFF. A total of 22 potential independent variables were put into a model with multivariate logistic regression analysis. A final reduced model following utilizing a stepwise backward selection strategy with pvalues $<0.2$ indicated preoperative elevated PAP (OR: 1.84, 95\%CI: $1.12-3.00, \mathrm{p}=0.016$ ), AV valve repair at Fontan (OR: 65.85, 95\%CI: 1.95-2228.14, $\mathrm{p}=0.020)$, and postoperative elevated PAP (OR: 1.66, 95\%CI: 1.19-2.33, $\mathrm{p}=0.004$ ) were independent predictors for $\mathrm{EFF}$. In conclusion, EFF is relatively high in our series, and is associated with significant mortality. Patients with a single ventricle physiology undergoing preoperative elevated PAP, AV valve repair at Fontan, and postoperative elevated PAP were identified as independent risk factors to predict EFF following a Fontan operation.

Keywords: Predictors; early Fontan failure; death; Fontan takedown

\section{I. ĐẠT VẤN ĐỀ}

Thất bại với tuần hoàn Fontan giai đoạn sớm (EFF) được xác định bởi tình trạng giảm tưới máu và cung lượng tuần hoàn, tăng áp lực trong hệ thống Fontan và cần bù lượng lớn thể tích dịch trong lòng mạch. Với những đặc điểm sinh lý này, khả năng đáp ứng của tuần hoàn Fontan với các thuốc vận mạch rất hạn chế và là nguyên nhân chính dẫn đến tử vong sau mổ. Trong những báo cáo về kết quả phẫu thuật Fontan giai đoạn đầu, tỉ lệ EFF trong các nghiên cứu cao hơn ngưỡng $10 \%$, với tỉ lệ tử vong dao động từ 9-15\% [1-4]. Có nhiều chiến lược điều trị được tiến hành nhằm giảm tỉ lệ tử vong, chủ yếu thông qua việc chỉ định phẫu thuật có chọn lọc và hạn chế phẫu thuật Fontan với nhóm bệnh nhân "nguy cơ cao" [5], hoặc chấm dứt tuần hoàn Fontan sớm khi có nguy cơ EFF [2-18] và sử dụng phương pháp oxy hóa qua màng ngoài cơ thể (ECMO) như một biện pháp cầu nối trước khi tiến hành chấm dứt tuần hoàn Fontan hoặc tạo điều kiện chờ đợi cho cơ thể tự thích nghi và hồi phục $[8,9,12,14,19$ 21]. Trong những nghiên cứu gần đây, tỉ lệ sống sót nhờ ECMO và/hoặc tiến hành chấm dứt tuần hoàn Fontan dao động trong khoảng 33-66\% tùy báo cáo [8-11, 15, 19, 20].

Theo thời gian, sự cải tiến về kỹ thuật phẫu thuật, hiểu biết của các bác sỹ lâm sàng về đặc điểm sinh lý tuần hoàn Fontan và đưa ra những chiến lược điều trị thích hợp đã giải quyết được phần nào một số yếu tố nguy cơ của EFF sau mổ. Các yếu tố nguy cơ thường gặp trong các báo cáo về phẫu thuật Fontan bao gồm hội chứng Heterotaxy $[4,6,12]$, kiểu hình tâm thất hệ thống là thất phải $[12,16]$, van nhĩ- thất chung $[4,22]$, tăng áp lực động mạch phổi trước mổ [2-5, 14, 15], tăng áp lực cuối tâm trương tâm thất hệ thống $[1,3]$, phẫu thuật phương pháp sử dụng ống mạch ngoài tim $[6,8]$, tăng áp lực hệ thống Fontan sau mổ $[1,3,4]$, thời gian chạy máy tuần hoàn ngoài cơ thể kéo dài $[12,13]$, thời gian kẹp động mạch chủ trong mổ kéo dài $[3,8,13]$. Tuy nhiên những báo cáo về kết quả phẫu thuật Fontan giai đoạn sớm tại những nước có điều kiện cơ sở vật chất thiếu thốn hiện nay vẫn rất hạn chế. Nghiên cứu trước của tác giả Đỗ Anh Tiến đã báo cáo kết quả phẫu thuật Fontan tại Trung tâm tim mạch - Bệnh viện E, nhưng các yếu tố nguy cơ đến EFF còn chưa được báo cáo, cũng như các biến số nghiên cứu còn chưa đầy đủ [22]. Do đó, lần đầu tiên tại Việt Nam, chúng tôi tiến hành nghiên cứu nhằm xác định tỉ lệ EFF sau phẫu thuật Fontan trên nhóm bệnh nhân tim sinh lý một thất, đồng thời xác định một số yếu tố nguy cơ liên quan mật thiết với EFF sau mổ. 


\section{II. ĐỐI TƯợNG VÀ PHƯƠNG PHÁP NGHIÊN CÚU}

Đối tượng nghiên cứu

Dữ liệu được thu thập từ hồ sơ bệnh án của 145 bệnh nhân liên tiếp được chẩn đoán tim sinh lý 1 thất và được tiến hành phẫu thuật Fontan với ống mạch ngoài tim tại Bệnh viện
E (Hà Nội, Việt Nam) trong 8 năm từ tháng $8 / 2012$ đến hết $12 / 2019$. Tiêu chuẩn lựa chọn bệnh nhân tiến hành phẫu thuật Fontan được mô tả đầy đủ trong bảng 1 . Những trường hợp gia đình bệnh nhân không đồng ý tham gia được loại trừ khỏi nghiên cứu.

Bảng 1. Tiêu chuẩn lựa chọn bệnh nhân tiến hành phẫu thuật Fontan.

- Tất cả các bệnh nhân được chẩn đoán tim sinh lý 1 thất và đã trải qua phẫu thuật Glenn ở các giai đoạn trước đó.

- Bệnh nhân từ 2 tuổi trở lên, không phân biêt giới tính.

- Áp lực động mạch phổi trung bình $\leq 20 \mathrm{mmHg}$

- Kháng trở hệ mạch máu phổi $\leq 4 \mathrm{Wood}$ unit $/ \mathrm{m}^{2}$

- Chỉ số kích thước động mạch phổi $(\mathrm{PAI}) \geq 150$ và không có bất thường về giải phẫu cây động mạch phổi bao gồm hẹp mức độ từ vừa trở lên các nhánh tại mức rốn phổi.

- Chức năng co bóp tâm thất trong giới hạn bình thường (phân suất tống máu >50\%)

• Van nhĩ thất không hẹp, không hở hoặc hở mức độ nhẹ- vừa.

- Tĩnh mạch chủ dưới kết nối với tâm nhĩ chung.

• Nhịp cơ bản là nhịp xoang hoặc nhịp nhĩ với trường hợp đồng phân trái.

\section{Chiến lược điều trị}

Tất cả các bệnh nhân được chẩn đoán tim bẩm sinh dạng sinh lý 1 thất được trải qua phẫu thuật 3 giai đoạn. Ở giai đoạn 1 , các phương pháp phẫu thuật được áp dụng bao gồm: phương pháp tạo shunt cấp máu cho phổi; phẫu thuật Banding động mạch phổi; phẫu thuật tạo hình động mạch phổi; phẫu thuật Damus- Kaye- Stansel (DKS), phẫu thuật Norwood, phẫu thuật tạo hình eo động mạch chủ, phẫu thuật sửa hồi lưu tĩnh mạch phổi, sửa van nhĩ-thất. Giai đoạn 2 , tất cả các bệnh nhân được tiến hành phẫu thuật Glenn 2 hướng (nối tĩnh mạch chủ trên và động mạch phổi). Thông tim đánh giá huyết động được tiến hành thường quy trước khi phẫu thuật Glenn, tuy nhiên do dữ liệu không đầy đủ nên các thông số huyết động ở giai đoạn này không được phân tích trong nghiên cứu. Giai đoạn 3 , các bệnh nhân đủ tiêu chuẩn sẽ được tiến hành phẫu thuật Fontan với ống mạch ngoài tim. Trước khi phẫu thuật, các chỉ số liên quan đến tiền sử, thăm khám lâm sàng, khảo sát cấu trúc giải phẫu qua siêu âm Doppler và thăm dò huyết động qua thông tim chụp mạch được ghi nhận. Trong quá trình phẫu thuật Fontan, các thủ thuật được tiến hành kèm theo bao gồm: phẫu thuật tạo cửa sổ, phẫu thuật tạo hình động mạch phổi, mở rộng vách liên nhĩ, thủ thuật DKS, sửa hoặc thay van nhĩ thất, xử lý tuần hoàn bàng hệ chủ phổi bằng phương pháp cắt hoặc thắt. Sau phẫu thuật Fontan, các bệnh nhân được điều trị hồi sức theo phác đồ, ưu tiên việc hạn chế hỗ trợ thông khí nhận tạo càng sớm càng tốt, liệu pháp lợi tiểu và hạn chế dịch, thở oxy bằng gọng mũi và sử dụng thuốc hỗ trợ (vận mạch, kháng sinh, giảm đau...) nếu cần thiết. Tất cả các bệnh nhân được uống aspirin với liều 3$5 \mathrm{mg} / \mathrm{kg} /$ ngày thay thế heparin duy trì nhằm mục đích chống đông máu. Dẫn lưu màng phổi được rút khi lượng dịch dẫn lưu dưới $2 \mathrm{ml} / \mathrm{kg} /$ ngày và không có tắc nghẽn hệ thống dẫn lưu. 


\section{Biến số phụ thuộc}

Biến số được nghiên cứu chính về kết quả đầu ra sau phẫu thuật là tình trạng thất bại với tuần hoàn Fontan giai đoạn sớm (EFF), được định nghĩa là 1 trong 3 trường hợp: tử vong, hoặc chấm dứt tuần hoàn Fontan, hoặc lên kế hoạch ghép tim trong khoảng thời gian từ khi mổ đến trước khi ra viện hoặc trong vòng 30 ngày kể từ khi được phẫu thuật. Các yếu tố nguy cơ được khảo sát dựa trên quá trình thu thập dữ liệu về lâm sàng, cận lâm sàng tại thời điểm trước, trong và sau mổ trong điều kiện hiện có tại cơ sở thực hành.

\section{Xử lý số liệu}

Số liệu thô từ phiếu được nhập liệu bằng phần mềm Epidata 3.1, sau đó được xử lý bằng phần mềm Stata ${ }^{\circledR} 15$ (StataCorp LLC, USA). Các biến liên tục được trình bày dưới dạng trung bình, độ lệch chuẩn, và phạm vi dữ liệu. Các biến thứ hạng được trình bày dưới dạng tần số và phần trăm. Phân tích hồi quy đơn biến được sử dụng xác định các yếu tố liên quan đến EFF. Tổng cộng có 22 biến hợp lệ tại các thời điểm trước Fontan, trong Fontan và sau Fontan được coi là các biến độc lập được đưa vào mô hình đầy đủ với phân tích hồi quy logistic đa biến. Chúng tôi sử dụng chiến lược stepwise backward với giá trị $\mathrm{p}<0,2$; sau đó một mô hình rút gọn với hồi quy logistic đa biến tối giản được thiết lập. Giá trị $\mathrm{p}$ $<0,05$ được coi là có ý nghĩa thống kê.

\section{Đạo đức nghiên cứu}

Tất cả các quy trình được thực hiện trong nghiên cứu theo Tuyên bố Helsinki năm 1964. Nghiên cứu này đã được phê duyệt bởi Hội Đồng Đạo đức của Đại học Y Hà Nội. Tất cả những người tham gia trong nghiên cứu đã nhận được sự đồng ý.

\section{KÊTT QUẢ NGHIÊN CƯU}

Bảng 2. Danh sách nhóm bệnh nhân EFF sau mổ

\begin{tabular}{cccccccc}
\hline $\begin{array}{c}\text { Số thứ } \\
\text { tự }\end{array}$ & $\begin{array}{c}\text { Năm } \\
\text { mổ }\end{array}$ & ECMO & $\begin{array}{c}\text { Chấm dứt } \\
\text { Fontan }\end{array}$ & $\begin{array}{c}\text { Ghép } \\
\text { tim }\end{array}$ & $\begin{array}{c}\text { Tử } \\
\text { vong }\end{array}$ & $\begin{array}{c}\text { Nguyên } \\
\text { nhân }\end{array}$ & Theo dõi \\
\hline 1 & 2014 & - & - & - & + & $(1)$ & $\mathrm{n} / \mathrm{a}$ \\
2 & 2014 & - & - & - & + & $(3)$ & $\mathrm{n} / \mathrm{a}$ \\
3 & 2015 & - & - & - & + & $(4)$ & $\mathrm{n} / \mathrm{a}$ \\
4 & 2016 & - & - & - & + & $(2)$ & $\mathrm{n} / \mathrm{a}$ \\
5 & 2016 & - & - & - & + & $(1),(2)$ & $\mathrm{n} / \mathrm{a}$ \\
6 & 2017 & - & - & - & + & $(4)$ & $\mathrm{n} / \mathrm{a}$ \\
7 & 2017 & - & - & - & + & $(1),(2)$ & $\mathrm{n} / \mathrm{a}$ \\
8 & 2017 & - & - & - & + & $(1),(2)$ & $\mathrm{n} / \mathrm{a}$ \\
9 & 2017 & - & - & - & + & $(1)$ & $\mathrm{n} / \mathrm{a}$ \\
10 & 2018 & - & - & - & + & $(1)$ & $\mathrm{n} / \mathrm{a}$ \\
11 & 2018 & - & - & - & + & $(1),(2)$ & $\mathrm{n} / \mathrm{a}$ \\
12 & 2018 & - & - & - & + & $(2),(3)$ & $\mathrm{n} / \mathrm{a}$ \\
13 & 2018 & - & - & - & + & $(2),(5)$ & $\mathrm{n} / \mathrm{a}$ \\
14 & 2019 & - & + & - & - & $(1)$ & Sống sót đến thời điểm hiện tại \\
\hline
\end{tabular}

ECMO: oxy hóa màng ngoài cơ thể

(1) rối loạn huyết động không đáp ứng điều trị; ${ }^{(2)}$ suy đa tạng; ${ }^{(3)}$ nhiễm khuẩn huyết và shock nhiễm khuẩn; ${ }^{(4)}$ ngừng tuần hoàn do rối loạn nhịp; ${ }^{(5)}$ nhồi máu não. 
Kết quả sau mổ của nhóm bệnh nhân EFF được tổng hợp trong bảng 2. Tỉ lệ EFF trong nghiên cứu là $9,66 \%$ (14/135 bệnh nhân). Trong số này, 13 trường hợp tử vong (chiếm 92,86\%). So với tổng số nghiên cứu, tỉ lệ tử vong nói chung là 8,97\%. Một bệnh nhân EFF được tiến hành phẫu thuật chấm dứt tuần hoàn Fontan, chuyển trở lại dạng Glenn 2 hướng như trước mổ và không cần sử dụng ECMO hỗ trợ. Thời gian kể từ khi phẫu thuật Fontan đến thời điểm chấm dứt tuần hoàn Fontan là 2 ngày. Nguyên nhân chính dẫn đến EFF trên bệnh nhân này là rối loạn huyết động không đáp ứng với điều trị. $57,14 \%$ trong nhóm EFF tìm được 1 nguyên nhân, số còn lại xác định được 2 nguyên nhân khác nhau dẫn tới EFF. $57,14 \%$ bệnh nhân EFF có rối loạn huyết động, $50 \%$ có tình trạng suy đa tạng và $14,29 \%$ trường hợp thất bại do nhiễm khuẩn huyết và shock nhiễm trùng. Ngoài ra có 2 bệnh nhân được chẩn đoán ngừng tuần hoàn do các rối loạn nhịp cấp tính, và 1 bệnh nhân được chẩn đoán nhồi máu não lớn sau mổ.

Các biến số trước mổ được nghiên cứu giữa 2 nhóm bệnh nhân có và không có tình trạng EFF sau mổ được so sánh với kết quả thu được mô tả trong bảng 3. Phân tích đơn biến xác định được một số yếu tố nguy cơ có liên hệ mật thiết với EFF sau mổ bao gồm: thể bệnh thông sàn nhĩ thất thể không cân xứng (OR: 5.39, 95\%CI: $1.66-$ $17.55, \mathrm{p}=0.005)$, bất thường đảo ngược phủ tạng OR: $3.68,95 \%$ CI: $1.07-12.58, \mathrm{p}=0.038$ ), hở van nhĩ- thất trước mổ (OR: 4.63, 95\%CI: $1.45-$ $14.85, \mathrm{p}=0.01$ ), tuần hoàn bàng hệ chủ- phổi lớn phát hiện trên siêu âm (OR: 6.72, 95\%CI: 1.89 23.92, $\mathrm{p}=0.003)$, tình trạng tăng áp lực động mạch phổi (OR: 1.40, 95\%CI: 1.08 - 1.82, $\mathrm{p}=0.011)$ và tăng sức cản hệ mạch máu phổi trước mổ (OR: 6.73, 95\%CI: $1.65-27.39, \mathrm{p}=0.008)$.

Bảng 3. Yếu tố nguy cơ trước mổ của tình trạng EFF: Phân tích đơn biến

\begin{tabular}{|c|c|c|c|c|c|c|c|}
\hline \multirow[t]{2}{*}{ Biến số trước mổ } & \multicolumn{2}{|c|}{ EFF $(n=14)$} & \multicolumn{2}{|c|}{ Không EFF $(n=131)$} & \multicolumn{3}{|c|}{ Phân tích đơn biến } \\
\hline & Count & $\%$ of total & Count & $\%$ of total & OR & $95 \%$ CI & p value \\
\hline \multicolumn{8}{|l|}{ Giới } \\
\hline Nam & 6 & 42.86 & 79 & 60.31 & 1 & - & \\
\hline Nũ̃ & 8 & 57.14 & 52 & 39.7 & 2.03 & $0.66-6.18$ & 0.215 \\
\hline Liệt cơ hoành & 0 & 0.00 & 1 & 0.76 & - & - & \\
\hline $\begin{array}{l}\text { Tràn dịch màng phổi } \\
\text { kéo dài }\end{array}$ & 0 & 0.00 & 3 & 2.29 & - & - & \\
\hline Tràn dịch dưỡng chấp & 0 & 0.00 & 1 & 0.76 & - & - & \\
\hline Gây dính màng phổi & 0 & 0.00 & 1 & 0.76 & - & - & \\
\hline $\begin{array}{l}\text { Biến chứng thần kinh } \\
\text { Suy tim }\end{array}$ & 0 & \multicolumn{5}{|c|}{ Suy tim ${ }^{*}$} & \\
\hline Độ II & 6 & 42.86 & 67 & 51.15 & 1 & - & \\
\hline Độ III & 8 & 57.14 & 64 & 48.85 & 1.40 & $0.46-4.25$ & 0.557 \\
\hline \multicolumn{8}{|l|}{ Điện tâm đồ } \\
\hline Nhịp xoang & 14 & 100.00 & 120 & 91.60 & - & - & \\
\hline Nhịp nhĩ & 0 & 0.00 & 5 & 3.82 & - & - & \\
\hline Nhịp bộ nối & 0 & 0.00 & 6 & 4.58 & - & - & \\
\hline \multicolumn{8}{|l|}{$\begin{array}{l}\text { Thể bệnh tim sinh lý } \\
1 \text { thất }\end{array}$} \\
\hline Teo van ba lá & 1 & 7.14 & 23 & 17.56 & 0.36 & $0.04-2.90$ & 0.338 \\
\hline Teo/thiểu sản van hai lá & 0 & 0.00 & 10 & 7.63 & - & - & \\
\hline Thất 2 đường vào & 1 & 7.14 & 20 & 15.27 & 0.43 & $0.05-3.45$ & 0.425 \\
\hline Bệnh Ebstein & 1 & 7.14 & 3 & 2.29 & 3.28 & $0.32-33.87$ & 0.318 \\
\hline
\end{tabular}




\begin{tabular}{|c|c|c|c|c|c|c|c|}
\hline $\begin{array}{l}\text { Teo phổi lành vách } \\
\text { liên thất }\end{array}$ & 0 & 0.00 & 3 & 2.29 & - & - & \\
\hline $\begin{array}{l}\text { Đảo gốc động mạch có } \\
\text { sửa chữa }\end{array}$ & 1 & 7.14 & 9 & 6.87 & 1.04 & $0.12-8.89$ & 0.969 \\
\hline $\begin{array}{l}\text { Thất phải } 2 \text { đường ra có } \\
\text { đảo gốc }\end{array}$ & 2 & 14.29 & 41 & 31.30 & 0.37 & $0.08-1.71$ & 0.201 \\
\hline $\begin{array}{l}\text { Thông sàn nhĩ thất thể } \\
\text { không cân xứng }\end{array}$ & 6 & 42.86 & 16 & 12.21 & 5.39 & $1.66-17.55$ & 0.005 \\
\hline $\begin{array}{l}\text { Thông sàn nhĩ thất kèm } \\
\text { đảo gốc } \\
\text { Tư thế tạng ngực- bụng }\end{array}$ & 2 & 14.29 & 6 & 4.58 & 3.47 & $0.63-19.13$ & 0.153 \\
\hline Situs solitus & 8 & 57.14 & 100 & 76.34 & 1 & - & \\
\hline $\begin{array}{l}\text { Situs inversus (đảo } \\
\text { ngược phủ tạng) }\end{array}$ & 5 & 35.71 & 17 & 12.98 & 3.68 & 1.07- 12.58 & $\mathbf{0 . 0 3 8}$ \\
\hline $\begin{array}{l}\text { Situs ambiguous (đồng } \\
\text { phân) } \\
\text { Kiếu hình tâm thất hệ } \\
\text { thống }\end{array}$ & 1 & 7.14 & 14 & 10.69 & 0.89 & $0.10-7.69$ & 0.918 \\
\hline Thất phải & 7 & 50.00 & 28 & 21.37 & 1 & - & \\
\hline Thất trái & 2 & 14.29 & 33 & 25.19 & 0.24 & $0.05-1.26$ & 0.092 \\
\hline 2 thất & 5 & 35.71 & 53 & 40.46 & 0.38 & $0.11-1.30$ & 0.122 \\
\hline $\begin{array}{l}\text { Không xác định kiểu } \\
\text { hình } \\
\text { Số van nhĩ thất }\end{array}$ & 0 & 0.00 & 17 & 12.98 & - & - & \\
\hline Một van & 10 & 71.43 & 59 & 45.04 & 1 & - & \\
\hline Hai van & 4 & 28.57 & 72 & 54.96 & 0.33 & $0.10-1.10$ & 0.071 \\
\hline $\begin{array}{l}\text { Tình trạng hở van nhĩ } \\
\text { thất }\end{array}$ & & & & & & & \\
\hline Hở nhẹ & 6 & 42.86 & 73 & 55.73 & 1 & - & \\
\hline Hở vừa & 8 & 57.14 & 21 & 16.03 & 4.63 & 1.45- 14.85 & 0.01 \\
\hline Không hở & 0 & 0.00 & 37 & 28.24 & - & - & \\
\hline Đặc điểm van nhĩ thất & & & & & & & \\
\hline Van tự nhiên & 14 & 100.00 & 127 & 96.95 & - & - & \\
\hline Van cơ học & 0 & 0.00 & 1 & 0.76 & - & - & \\
\hline Van sinh học & 0 & 0.00 & 3 & 2.29 & - & - & \\
\hline $\begin{array}{l}\text { Cản trở đường ra tuần } \\
\text { hoàn hệ thống }\end{array}$ & 0 & 0.00 & 8 & 6.11 & - & - & \\
\hline Hẹp dưới van chủ & 0 & 0.00 & 5 & 3.82 & - & - & \\
\hline Thông liên thất hạn chế & 0 & 0.00 & 3 & 2.29 & - & - & \\
\hline $\begin{array}{l}\text { Hẹp miệng nối tĩnh } \\
\text { mạch chủ trên- động } \\
\text { mạch phổi }\end{array}$ & 1 & 7.14 & 0 & 0.00 & - & - & \\
\hline $\begin{array}{l}\text { Bất thường giải phẫu } \\
\text { động mạch phổi }\end{array}$ & 0 & 0.00 & 1 & 0.76 & - & - & \\
\hline Còn ống động mạch & 0 & 0.00 & 2 & 1.53 & - & - & \\
\hline $\begin{array}{l}\text { Tuần hoàn bàng hệ chủ- } \\
\text { phổi lớn trên siêu âm }\end{array}$ & 5 & 35.71 & 10 & 7.63 & 6.72 & 1.89- 23.92 & 0.003 \\
\hline $\begin{array}{l}\text { Shunt thất- động mạch } \\
\text { phổi tồn lưu }\end{array}$ & 4 & 28.57 & 46 & 35.11 & 0.74 & $0.22-2.49$ & 0.625 \\
\hline $\begin{array}{l}\text { Tuần hoàn bàng hệ chủ- } \\
\text { phổi lớn trên thông tim }\end{array}$ & 7 & 50.00 & 43 & 32.82 & 2.05 & $0.67-6.21$ & 0.206 \\
\hline
\end{tabular}




\begin{tabular}{|c|c|c|c|c|c|c|c|}
\hline & Mean \pm SD & Range & Mean \pm SD & Range & OR & $95 \%$ CI & p value \\
\hline Tuổi (tháng) & $67.71 \pm 63.71$ & $28-240$ & $68.11 \pm 53.15$ & $24-426.7$ & 1.00 & $0.99-1.01$ & 0.979 \\
\hline Chiều cao (cm) & $95 \pm 33.88$ & $10-155$ & $103.4 \pm 18.0$ & $80-165$ & 0.98 & $0.95-1.01$ & 0.137 \\
\hline Cân nặng (kg) & $17.2 \pm 12.0$ & $9-51$ & $16.4 \pm 7.7$ & $8.5-49.5$ & 1.01 & $0.95-1.08$ & 0.726 \\
\hline $\begin{array}{l}\text { Áp lực động mạch phổi } \\
\text { trung bình }(\mathrm{mmHg})(\mathrm{n}= \\
142)\end{array}$ & $12.86 \pm 1.66$ & $11-16$ & $11.26 \pm 2.16$ & $7-17$ & 1.40 & $1.08-1.82$ & 0.011 \\
\hline $\begin{array}{l}\text { Áp lực cuối tâm trương } \\
\text { thất hệ thống }(\mathrm{mmHg}) \\
(\mathrm{n}=129)\end{array}$ & $4.85 \pm 1.34$ & $2-6$ & $5.07 \pm 1.65$ & $2-12$ & 0.92 & $0.62-1.33$ & 0.637 \\
\hline $\begin{array}{l}\text { Chỉ số kích thược động } \\
\text { mạch phổi PAI (n= 137) }\end{array}$ & $336.93 \pm 230.66$ & $170-1037$ & $322.6 \pm 100.23$ & $140-676$ & 1.00 & $0.99-1.01$ & 0.669 \\
\hline $\begin{array}{l}\text { Sức cản hệ mạch máu } \\
\text { phổi Rp } \quad\left(\text { wood } / \mathrm{m}^{2}\right) \\
(\mathrm{n}=64)\end{array}$ & $2.66 \pm 0.55$ & $1.6-3.7$ & $1.79 \pm 0.77$ & $0.3-3.3$ & 6.73 & 1.65- 27.39 & 0.008 \\
\hline
\end{tabular}

*NYHA Heart Failure Classification; EFF: early Fontan failure; PAI: pulmonary artery index; Rp: Pulmonary vascular resistance; OR: odd ratio; 95\%CI: 95\% confidence interval

Bảng 4. Yếu tố nguy cơ trong và sau mổ của tình trạng EFF: Phân tích đơn biến

\begin{tabular}{|c|c|c|c|c|c|c|c|}
\hline \multirow[t]{2}{*}{ Biến số } & \multicolumn{2}{|c|}{$\begin{array}{l}\text { Fontan failure } \\
\quad(n=14)\end{array}$} & \multicolumn{2}{|c|}{$\begin{array}{l}\text { No Fontan failure } \\
\quad(n=131)\end{array}$} & \multicolumn{3}{|c|}{ Univariate analysis } \\
\hline & Count & $\%$ of total & Count & $\begin{array}{l}\% \text { of } \\
\text { total }\end{array}$ & OR & $95 \% \mathrm{CI}$ & p value \\
\hline \multicolumn{8}{|l|}{ Trong mổ Fontan } \\
\hline Tạo hình động mạch phổi & 4 & 28.57 & 11 & 8.4 & 4.36 & $1.17-16.23$ & 0.028 \\
\hline Thủ thuật DKS & 1 & 7.14 & 3 & 2.29 & 3.28 & $0.32-33.87$ & 0.318 \\
\hline Sửa van nhĩ thất & 3 & 21.43 & 1 & 0.76 & 35.45 & $\begin{array}{l}3.40 \\
370.04\end{array}$ & -0.003 \\
\hline Thay van nhĩ thất & 0 & 0.00 & 1 & 0.76 & - & - & \\
\hline Mở rộng vách liên nhĩ & 0 & 0.00 & 16 & 12.21 & - & - & \\
\hline Cắt APCA & 0 & 0.00 & 1 & 0.76 & - & - & \\
\hline Thắt APCA & 0 & 0.00 & 1 & 0.76 & - & - & \\
\hline \multicolumn{8}{|l|}{$\begin{array}{l}\text { Loại ống Fontan được sử } \\
\text { dụng }\end{array}$} \\
\hline Gortex & 4 & 28.57 & 66 & 50.38 & 1 & - & \\
\hline Unigraff & 10 & 71.43 & 65 & 49.62 & 2.54 & $0.76-8.50$ & 0.131 \\
\hline Có cặp động mạch chủ & 14 & 100.00 & 112 & 85.50 & - & - & \\
\hline Chảy máu & 4 & 28.57 & 3 & 2.29 & 17.07 & $3.35-87.06$ & 0.001 \\
\hline \multicolumn{8}{|l|}{ Sau mổ Fontan } \\
\hline Phù & 4 & 28.57 & 5 & 3.28 & 10.08 & $2.33-43.58$ & 0.002 \\
\hline $\begin{array}{l}\text { Tràn dịch kéo dài >14 } \\
\text { ngày }\end{array}$ & 0 & 0.00 & 29 & 22.14 & - & - & \\
\hline
\end{tabular}




\begin{tabular}{lccccccc}
\hline & Mean \pm SD & Range & Mean \pm SD & Range & OR & $\mathbf{9 5 \%}$ CI & p value \\
\hline $\begin{array}{l}\text { Trong mổ Fontan } \\
\text { Thời gian kẹp động mạch }\end{array}$ & $50.29 \pm 18.03$ & $17-76$ & $48.69 \pm 24.75$ & $3-168$ & 1.00 & $0.98-1.03$ & 0.814 \\
chủ (phút) \\
$\begin{array}{l}\text { Thời gian tuần hoàn } \\
\text { ngoài cơ thể (phút) }\end{array}$ & & & & & & \\
$\begin{array}{l}\text { Tổng thời gian chạy máy } \\
\text { hỗ trợ (phút) }\end{array}$ & $15.64 \pm 5.73$ & $10-30$ & $19.85 \pm 14.17$ & $6-84$ & 0.97 & $0.91-1.03$ & 0.276 \\
$\begin{array}{l}\text { PAP (mmHg) } \\
\text { Sau mổ Fontan }\end{array}$ & $17.41 \pm 3.02$ & $14-23$ & $14.85 \pm 3.43$ & $7-25$ & $\mathbf{1 . 2 3}$ & $\mathbf{1 . 0 7 - 1 . 4 8}$ & $\mathbf{0 . 0 0 5}$ \\
PAP (mmHg) & $20.29 \pm 5.48$ & $13-31$ & $15.8 \pm 9.58$ & $8-118$ & 1.03 & $0.99-1.07$ & 0.177
\end{tabular}

DKS: Damus-Kaye-Stansel; APCA: tuần hoàn bàng hệ chủ- phổi; PAP: áp lực động mạch phổi trung bình; OR: odd ratio; 95\%CI: 95\% confidence interval.

Các biến số trong và sau mổ được so sánh giữa 2 nhóm có và không có tình trạng EFF, kết quả được mô tả trong bảng 4. Phân tích đơn biến chỉ ra, tại thời điểm phẫu thuật Fontan, xác định được 4 yếu tố nguy cơ của tình trạng EFF bao gồm: tạo hình động mạch phổi (OR: 4.36, 95\%CI: 1.17 - 16.23, $\mathrm{p}=0.028)$, sửa van nhĩ thất (OR: $35.45,95 \% \mathrm{CI}: 3.40-370.04, \mathrm{p}=0.003)$, chảy máu trong mổ (OR: 17.07, 95\%CI: 3.35 - 87.06, p=0.001), tăng áp lực động mạch phổi (OR: 1.23, 95\%CI: $1.07-1.48$, $\mathrm{p}=0.005)$. Trong các biến số sau mổ, tình trạng phù có liên quan mật thiết với $\mathrm{EFF}(\mathrm{OR}: 10.08,95 \% \mathrm{CI}$ : $2.33-43.58, \mathrm{p}=0.002)$.

Bảng 5. Yếu tố nguy cơ độc lập liên quan đến tình trạng EFF sau mổ: phân tích đa biến

\begin{tabular}{|c|c|c|c|}
\hline \multirow{2}{*}{ Biến số } & \multicolumn{3}{|c|}{ Multivariate logistic regression } \\
\hline & OR & $95 \% \mathrm{CI}$ & p value \\
\hline \multicolumn{4}{|l|}{ Trước mổ } \\
\hline Tuổi & 1.06 & $0.99-1.12$ & 0.069 \\
\hline Chiều cao & 0.89 & $0.76-1.04$ & 0.153 \\
\hline $\begin{array}{l}\text { Tuần hoàn bàng hệ chủ- phổi lớn phát hiện trên siêu } \\
\text { âm (so với không có) }\end{array}$ & 1 & - & \\
\hline Có & 12.45 & $0.58-257.60$ & 0.107 \\
\hline Áp lực động mạch phổi lúc thông tim & 1.84 & $1.12-3.00$ & 0.016 \\
\hline \multicolumn{4}{|l|}{ Trong mổ } \\
\hline Sửa van nhĩ thất (so với không) & 1 & - & \\
\hline Có & 65.85 & $1.95-2228.14$ & 0.020 \\
\hline Chảy máu (so với không) & 1 & - & \\
\hline Có & 8.50 & $0.40-178.76$ & 0.168 \\
\hline \multicolumn{4}{|l|}{ Sau mổ } \\
\hline Áp lực động mạch phổi trung bình & 1.66 & $1.19-2.33$ & 0.004 \\
\hline
\end{tabular}

OR: odd ratio; 95\%CI: 95\% confidence interval 
Tổng số 22 biến độc lập (cả trước, trong và sau mổ) được tiến hành phân tích đa biến với kết quả mô tả trong bảng 5 . Xác định được 3 yếu tố độc lập có liên quan đến tình trạng $\mathrm{EFF}$ bao gồm: tăng áp lực động mạch phổi trước mổ (OR: 1.84, 95\%CI: $1.12-3.00, \mathrm{p}=0.016$ ), việc tiến hành phẫu thuật sửa van nhĩ thất cùng thời điểm phẫu thuật Fontan (OR: 65.85, 95\%CI: $1.95-2228.14, \mathrm{p}=0.020$ ), và sự gia tăng áp lực động mạch phổi trung bình sau mổ (OR: 1.66, 95\%CI: $1.19-2.33, \mathrm{p}=0.004)$.

\section{BÀN LUẬN}

Cùng với sự tiến bộ của y học nói chung và chuyên ngành phẫu thuật tim bẩm sinh nói riêng, ngày nay, phẫu thuật Fontan đạt được những kết quả rất đáng khích lệ về tỉ lệ sống sót, cải thiện chất lượng cuộc sống và tiên lượng lâu dài cho nhóm bệnh nhân tim bẩm sinh phức tạp. Tuy nhiên, tính tới hiện tại chưa có báo cáo nào về $\mathrm{EFF}$ tại các trung tâm phẫu thuật tim mạch trong khu vực Đông Nam Á. Do đó, nghiên cứu này được tiến hành với mục tiêu thu thập dữ liệu trước mổ, quá trình theo dõi và các giai đoạn phẫu thuật cũng như kết quả theo dõi hậu phẫu của nhóm bệnh nhân tim sinh lý một thất có chọn lọc, trong đó kết quả phẫu thuật giai đoạn sớm tập trung vào tình trạng thất bại với tuần hoàn Fontan $(\mathrm{EFF})$ nhằm xác định tỉ lệ và yếu tố nguy cơ liên quan với EFF sau mổ. Trong nghiên cứu này, tỉ lệ EFF được xác định là $9,66 \%$. Con số này có sự tương đồng với các báo cáo về phẫu thuật Fontan ở thời kỳ đầu [14], với các báo cáo về tỉ lệ EFF dao động trên $10 \%$ và tî̉ lệ tử vong dao động từ 9-15\%. Tuy nhiên, con số này trong các báo cáo thời gian gần đây thấp hơn rất nhiều [23], [24]. Có 2 nhóm nguyên nhân chính chúng tôi lý giải cho việc tỉ lệ EFF trong nghiên cứu cao hơn so với mặt bằng chung hiện tại. Thứ nhất, đây là những năm đầu tiên triển khai chiến lược phẫu thuật cho bệnh nhân tim sinh lý một thất tại cơ sở thực hành, đồng thời là khoảng thời gian các bác sỹ tim mạch tiếp cận, theo dõi, điều trị trực tiếp cho nhóm bệnh nhân này, do đó về kinh nghiệm điều trị và hồi sức sau mổ còn nhiều hạn chế. Thứ hai, do nguồn lực về điều kiện cơ sở chưa đầy đủ tại các quốc gia đang phát triển như Việt Nam, đa phần các bệnh nhân không được phát hiện bệnh sớm, được lên chiến lược và can thiệp sớm ngay từ sau sinh, do đó trong những giai đoạn đầu của liệu trình phẫu thuật Fontan diễn ra muộn, khi đó hệ thống mạch máu phổi và chức năng tim đã bị thay đổi theo chiều hướng tiêu cực và khó hồi phục, điều này cũng góp phần khiến cho kết quả sau phẫu thuật không như mong muốn.

Trong các báo cáo sau phẫu thuật Fontan, EFF là chỉ tiêu được khảo sát chính, tuy nhiên trong mỗi báo cáo có sự khác biệt về cách định nghĩa khái niệm về EFF khác nhau. Một số báo cáo đánh giá EFF bao gồm cả nhóm bệnh nhân cần sử dụng thuốc vận mạch kéo dài hoặc thở máy kéo dài [12]; một số khác loại bỏ tiêu chuẩn những bệnh nhân sử dụng ECMO [6]. Tỉ lệ sống sót trên nhóm bệnh nhân EFF dao động trong khoảng rất rộng, được tóm tắt trong bảng 6 . 
Bảng 6. Báo cáo về EFF sau mổ Fontan trên thế giới

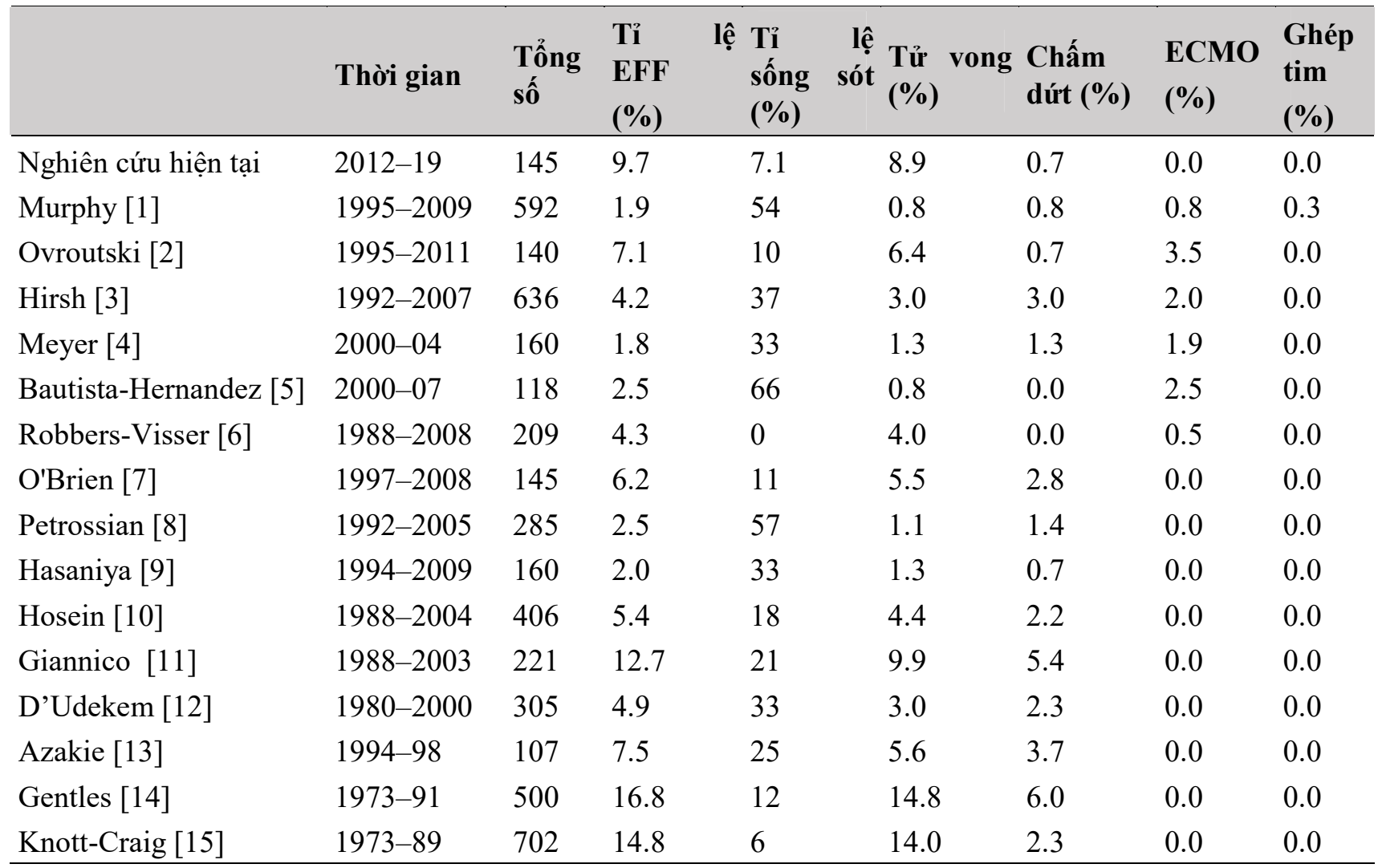

Nghiên cứu đưa ra kết quả, thể bệnh tim bẩm sinh dạng thông sàn nhĩ thất toàn bộ thể không cân xứng là yếu tố tiên lượng cho EFF. Đa phần các trường hợp là thiểu sản thất trái, tâm thất hệ thống kiểu hình thất phải và một vòng van. Do đó, về lâu dài, các trường hợp này thường có chức năng tâm thất hệ thống không được đảm bảo. Đã từ lâu, tình trạng hở van nhĩ thất hệ thống được biết đến góp phần vào tiên lượng không tốt sau mổ [26], [27]. Hở van nhĩ thất kéo dài làm suy giảm chức năng của tâm thất hệ thống từ trước khi tiến hành phẫu thuật Fontan. Ngoài ra, chúng tôi muốn nhấn mạnh vai trò của các tuần hoàn bàng hệ chủ- phổi lớn hoặc tuần hoàn dạng búi, đều có sự ảnh hưởng không tốt đến dòng chảy và sức cản hệ thống mạch máu phổi. Điều này góp phần giải thích lý do về sự tương quan giữa việc phát hiện tuần hoàn bàng hệ chủ- phổi lớn với $\mathrm{EFF}$ trong nghiên cứu.
Mặc dù có sự thay đổi về chiến lược phẫu thuật, tình trạng tăng áp lực động mạch phổi và kháng trở hệ mạch máu phổi vẫn là những yếu tố nguy cơ hàng đầu cho sự thất bại trong việc thích nghi với tuần hoàn Fontan ở cả giai đoạn sớm và giai đoạn muộn. Theo kết quả được báo cáo trong một số nghiên cứu, áp lực động mạch phổi trung bình $>15-18 \mathrm{~mm} \mathrm{Hg}$ và kháng trở hệ mạch máu phổi $>2-4$ đơn bị Wood $/ \mathrm{m}^{2}$ da làm gia tăng tỉ lệ tử vong sau mổ [29], [30]. Chiến lược giúp cải thiện tình trạng này sẽ góp phần tạo điều kiện thuận lợi cho quá trình điều trị sau mổ. Trong nghiên cứu, chúng tôi đánh giá áp lực động mạch phổi và sức cản hệ mạch máu phổi như một biến liên tục và phân tích nhằm xác định vai trò độc lập có liên quan với tình trạng EFF sau mổ. Với nhóm bệnh nhân có áp lực động mạch phổi cao đo trên thông tim, nguy cơ cao của việc cần can thiệp điều trị bằng thuốc, được chứng minh là yếu tố độc lập 
tiên lượng cho EFF. Kết quả này có sự đồng nhất với nhiều nghiên cứu đã được báo cáo trước đây [5], [14], [15], [17]. Trong nhóm bệnh tim sinh lý một thất, áp lực động mạch phổi cao có thể là hệ quả từ nhiều nguyên nhân khác nhau, như tăng lưu lượng máu lên phổi, tăng áp hậu mao mạch do cản trở hệ thống tim trái, hoặc do hình thành các vi huyết khối trong hệ mạch máu phổi. Báo cáo của Kaza [31] và Ridderbos [32] chỉ ra tình trạng dày tổ thức cấu tạo nên thành động mạch phổi tăng dần theo thời gian sau phẫu thuật Fontan. Bên cạnh đó, áp lực động mạch phổi ngay sau mổ cũng được chứng minh là yếu tố nguy cơ độc lập của EFF dựa trên phân tích đa biến. Giá trị sức cản hệ mạch máu phổi được tính toán dựa vào thông số về áp lực động mạch phổi trung bình, áp lực mao mạch phổi bít và cung lượng tuần hoàn phổi. Trong nghiên cứu, sức cản hệ mạch máu phổi được đo đạc trên 64 bệnh nhân, và theo các báo cáo xác định tình trạng tăng sức cản hệ mạch máu phổi cũng là yếu tố nguy cơ của EFF [4].

Một số các yếu tố khác có liên quan với EFF được chứng minh trong nghiên cứu bao gồm phẫu thuật tạo hình động mạch phổi, phẫu thuật sửa van nhĩ thất, và chảy máu trong mổ. Việc tạo hình động mạch phổi là một thủ thuật khó và phức tạp, đặc biệt với các trường hợp bất thường nằm ở vị trí sâu trong mức rốn phổi, do đó nhiều trường hợp kết quả của việc tạo hình không được như tình trạng sinh lý bình thường. Điều này làm ảnh hưởng tiêu cực đến kết quả điều trị sau mổ. Trong nghiên cứu, có 4 trường hợp được tiến hành sửa van nhĩ thất tại thời điểm phẫu thuật Fontan. Với đặc điểm giải phẫu của tim sinh lý một thất, tổn thương van nhĩ thất rất đa dạng, có thể có một hay hai vòng van, nhiều vị trí bám với nhiều mép van không cùng nằm trong một mặt phẳng, do đó việc sửa van gặp rất nhiều khó khăn, đôi khi phải sửa nhiều lần. Tình trạng suy giảm hoạt động chức năng của van nhĩ thất (hở mức độ từ vừa trở lên hoặc đã trải qua phẫu thuật sửa hay thay van) từ lâu đã được xác định là yếu tố nguy cơ cho tiên lượng đầu ra không tốt sau mổ [26], [27], [33]. Tỉ lệ xuất hiện tình trạng hở van nhĩ thất mới ở các bệnh nhân đã trải qua phẫu thuật Fontan chưa thực sự được đánh giá chính xác, cũng như đánh giá nguy cơ tiên lượng việc cần tiến hành can thiệp van ở giai đoạn sau. Mặc dù các bệnh nhân được chẩn đoán hở van mức độ vừa có tỉ lệ EFF cao hơn so với nhóm hở van nhẹ, ảnh hưởng của tình trạng hở van vừa đến nặng giai đoạn muộn sau mổ chưa được đánh giá đầy đủ.

Trong quá trình hồi sức sau mổ, tình trạng phù- được chẩn đoán dựa trên khám lâm sàng có phù mặt và/hoặc phù toàn thân có kèm hay không tràn dịch đa màng- thường đi kèm với các triệu chứng nặng. Nguyên nhân của tình trạng phù chủ yếu do tăng áp lực trong tĩnh mạch hệ thống. Nghiên cứu này cũng chỉ ra tình trạng phù sau phẫu thuật là yếu tố tiên lượng làm gia tăng nguy cơ EFF.

Để xác định các yếu tố tiên lượng độc lập với biến chứng EFF sau phẫu thuật Fontan, phân tích đa biến được tiến hành với 22 biến số trước, trong và sau mổ, từ đó rút ra kết quả 3 yếu tố làm gia tăng đáng kể tỉ lệ EFF, bao gồm tăng áp lực động mạch phổi trước mổ, sửa van nhĩ thất cùng thời điểm phẫu thuật Fontan và tăng áp lực động mạch phổi ngay sau mổ. Rất khó để tiến hành đối chiếu với các báo cáo khác trên thế giới, do trong một số báo cáo không sử dụng phương pháp phân tích đa biến [23], [24]. Sự không thống nhất về kết quả giữa các báo cáo chủ yếu do sự khác biệt về tiêu chuẩn lựa chọn bệnh nhân phẫu thuật, kinh nghiệm tại từng cơ sở, sự đa dạng về thể bệnh cũng như cỡ mẫu trong các nghiên cứu, và trong một số báo cáo có tỉ lệ EFF thấp, con số về biến chứng không đủ điều kiện tiến hành phân tích đánh giá yếu tố nguy cơ.

Trong điều kiện tại các quốc gia đang phát triển với nguồn lực hạn chế như tại Việt Nam, nghiên cứu này được tiến hành trước hết nhằm mục tiêu báo cáo kết quả trong những năm đầu 
tiên triển khai phẫu thuật Fontan cho nhóm bệnh nhân tim sinh lý một thất tại đơn vị trung tâm phẫu thuật tim mạch hiện hành. Bản thân chúng tôi ghi nhận một số điểm hạn chế của nghiên cứu. Thứ nhất, đây là nghiên cứu hồi cứu đơn trung tâm. Thứ hai, mặc dù rất nhiều các biến số được khảo sát và phân tích, một số chỉ số có tính trùng lặp hoặc không đồng nhất có thể vẫn tồn tại. Thứ ba, cỡ mẫu trong nghiên cứu còn tương đối hạn chế, dẫn đến hệ quy chiếu của nghiên cứu có thể không đầy đủ tính khách quan và phản ánh chính xác một số biến số, cũng như các yếu tố chủ quan, phức tạp và không đồng nhất do tiến trình phẫu thuật, hoặc các dữ liệu thu thập qua thông tim chụp mạch không đầy đủ. Điều cuối cùng, mặc dù các bệnh nhân được điều trị theo phác đồ chuẩn chung của bệnh tim sinh lý một thất, tuy nhiên nó vẫn được thực hiện với một nhóm nhỏ các bác sỹ tim mạch và phẫu thuật viên, do đó không có tính đại diện cho các cơ sở thực hành khác.

\section{KẾT LUẬN}

Nghiên cứu chỉ ra tỉ lệ EFF còn tương đối cao và liên quan mật thiết với tỉ lệ tử vong sau phẫu thuật Fontan ở nhóm bệnh nhân tim sinh lý 1 thất. Quá trình phân tích dữ liệu thu thập trước, trong và sau mổ đưa ra kết quả xác định 3 yếu tố nguy cơ độc lập làm gia tăng nguy cơ EFF, bao gồm tình trạng tăng áp lực động mạch phổi trước mổ, việc tiến hành phẫu thuật sửa van nhĩ thất trong mổ, và tăng áp lực động mạch phổi ngay sau mổ. Dựa trên kết quả này, việc xây dựng chiến lược điều trị đích nhằm hạn chế các yếu tố nguy cơ- bên cạnh các yếu tố đã biết trước đó- là điều rất cần thiết nhằm hạn chế EFF.

\section{TÀI LIỆU THAM KHẢO}

1. Cetta, F., et al., Improved early morbidity and mortality after Fontan operation: the Mayo Clinic experience, 1987 to 1992. Journal of the American College of Cardiology, 1996. 28(2): p. 480-486.
2. Mayer Jr, J.E., et al., Factors associated with marked reduction in mortality for Fontan operations in patients with single ventricle. The Journal of thoracic and cardiovascular surgery, 1992. 103(3): p. 444-452.

3. Knott-Craig, C.J., et al., The modified Fontan operation: an analysis of risk factors for early postoperative death or takedown in 702 consecutive patients from one institution. The Journal of thoracic and cardiovascular surgery, 1995. 109(6): p. 1237-1243.

4. Gentles, T.L., et al., Fontan operation in five hundred consecutive patients: factors influencing early and late outcome. The Journal of thoracic and cardiovascular surgery, 1997. 114(3): p. 376-391.

5. Hosein, R.B., et al., Factors influencing early and late outcome following the Fontan procedure in the current era. The 'Two Commandments'? European journal of cardiothoracic surgery, 2007. 31(3): p. 344-353.

6. Stewart, R.D., et al., Contemporary Fontan operation: association between early outcome and type of cavopulmonary connection. The Annals of thoracic surgery, 2012. 93(4): p. 1254-1261.

7. Tweddell, J.S., et al., Fontan palliation in the modern era: factors impacting mortality and morbidity. The Annals of thoracic surgery, 2009. 88(4): p. 1291-1299.

8. Hirsch, J.C., et al., Fontan operation in the current era: a 15-year single institution experience. Annals of surgery, 2008. 248(3): p. 402-410.

9. Hirsch, J., et al., The lateral tunnel Fontan procedure for hypoplastic left heart syndrome: results of 100 consecutive patients. Pediatric cardiology, 2007. 28(6): p. 426-432.

10. Hasaniya, N.W., et al., In situ pericardial extracardiac lateral tunnel Fontan operation: fifteen-year experience. The Journal of 
thoracic and cardiovascular surgery, 2010. 140(5): p. 1076-1083.

11. Petrossian, E., et al., The extracardiac conduit Fontan operation using minimal approach extracorporeal circulation: early and midterm outcomes. The Journal of thoracic and cardiovascular surgery, 2006. 132(5): p. 1054-1063.

12. Ovroutski, S., et al., Analysis of the risk factors for early failure after extracardiac Fontan operation. The Annals of thoracic surgery, 2013. 95(4): p. 1409-1416.

13. O'Brien Jr, J.E., et al., The nonfenestrated extracardiac Fontan procedure: a cohort of 145 patients. The Annals of thoracic surgery, 2010. 89(6): p. 1815-1820.

14. Iyengar, A.J., et al., The option of taking down the Fontan circulation: the Melbourne experience. Journal of thoracic and cardiovascular surgery (Print), 2010. 139(5): p. 1346-1348.

15. d'Udekem, Y., et al., The Fontan procedure: contemporary techniques have improved long-term outcomes. Circulation, 2007. 116(11_supplement): p. I-157-I-164.

16. Almond, C.S., et al., Outcome after Fontan failure and takedown to an intermediate palliative circulation. The Annals of thoracic surgery, 2007. 84(3): p. 880-887.

17. Rogers, L.S., et al., 18 years of the Fontan operation at a single institution: results from 771 consecutive patients. J Am Coll Cardiol, 2012. 60(11): p. 1018-25.

18. Giannico, S., et al., Clinical outcome of 193 extracardiac Fontan patients: the first 15 years. Journal of the American College of Cardiology, 2006. 47(10): p. 2065-2073.

19. Meyer, D.B., et al., Outcomes of the Fontan procedure using cardiopulmonary bypass with aortic cross-clamping. The Annals of thoracic surgery, 2006. 82(5): p. 1611-1620.

20. Bautista-Hernandez, V., et al., Right ventricle and tricuspid valve function at midterm after the Fontan operation for hypoplastic left heart syndrome: impact of shunt type. Pediatric cardiology, 2011. 32(2): p. 160-166.

21. Robbers-Visser, D., et al., Results of staged total cavopulmonary connection for functionally univentricular hearts; comparison of intra-atrial lateral tunnel and extracardiac conduit. European journal of cardio-thoracic surgery, 2010. 37(4): p. 934-941.

22. Đỗ Anh Tiến, Nghiên cứu ứng dụng phẫu thuật Fontan với ống nối ngoài tim điều trị tim bẩm sinh dạng một tâm thất tại Trung tâm tim mạch - Bệnh viện E. 2017, Đại học Y Hà Nội.

23. Rochelson, E., et al. Identification of risk factors for early Fontan failure. in Seminars in Thoracic and Cardiovascular Surgery. 2020. Elsevier.

24. Murphy, M.O., et al., Management of early Fontan failure: a single-institution experience. European Journal of Cardio-Thoracic Surgery, 2014. 46(3): p. 458-464.

25. Azakie, A., et al., Extracardiac conduit versus lateral tunnel cavopulmonary connections at a single institution: impact on outcomes. The Journal of thoracic and cardiovascular surgery, 2001. 122(6): p. 1219-1228.

26. Pundi, K.N., et al., 40-year follow-up after the Fontan operation: long-term outcomes of 1,052 patients. Journal of the American College of Cardiology, 2015. 66(15): p. 1700-1710.

27. d'Udekem, Y., et al., Predictors of survival after single-ventricle palliation: the impact of right ventricular dominance. Journal of the American College of Cardiology, 2012. 59(13): p. 1178-1185.

28. Diller, G.-P., et al., Predictors of morbidity and mortality in contemporary Fontan patients: results from a multicenter study including cardiopulmonary exercise testing in 321 patients. European heart journal, 2010. 31(24): p. 3073-3083. 
29. Giglia, T.M. and T. Humpl, Preoperative pulmonary hemodynamics and assessment of operability: is there a pulmonary vascular resistance that precludes cardiac operation? Pediatric Critical Care Medicine, 2010. 11: p. S57-S69.

30. Chowdhury, U.K., et al., Surgical outcome of staged univentricular-type repairs for patients with univentricular physiology and pulmonary hypertension. Indian Heart Journal, 2004. 56(4): p. 320-327.

31. Kaza, A.K., et al., Pulmonary vascular remodelling after heart transplantation in patients with cavopulmonary connection. European Journal of Cardio-Thoracic Surgery, 2015. 47(3): p. 505-510.

32. Ridderbos, F.-J.S., et al., Adverse pulmonary vascular remodeling in the Fontan circulation. The Journal of Heart and Lung Transplantation, 2015. 34(3): p. 404-413.

33. King, G., et al., Atrioventricular valve failure in Fontan palliation. Journal of the American College of Cardiology, 2019. 73(7): p. 810-822.

34. Schilling, C., et al., The Fontan epidemic: population projections from the Australia and New Zealand Fontan registry. International journal of cardiology, 2016. 219: p. 14-19. 